\title{
Numerical Simulation of Migration and Distribution Law for Gas Seepage in Coal Seam
}

\author{
Jiaxin Dong ${ }^{1,2}$, Lei Cheng ${ }^{1,2,3^{*}}$ \\ ${ }^{1}$ State Key Laboratory Cultivation Base for Gas Geology and Gas Control, Jiaozuo 454000, China \\ ${ }^{2}$ School of Safety Science and Engineering, Henan Polytechnic University, Jiaozuo 454000, China \\ ${ }^{3}$ Coal Production Safety Collaborative Innovation Center in Henan Province, Jiaozuo 454000, China
}

Corresponding Author Email: chengl@hpu.edu.cn

https://doi.org/10.18280/ijht.370312

Received: 15 March 2019

Accepted: 17 May 2019

\section{Keywords:}

gas pressure, gas migration, stress field, gas seepage, COMSOL multiphysics

\begin{abstract}
With the depletion of shallow coal resources, more and more coalmines are exploiting coal from deep coal seams. Under the coupling of multiple stress fields, the migration of gas underground will increase the gas content and pressure in the coal seam. However, there is little report on numerical simulation of gas migration. To make up for this gap, this paper probes deep into the seepage process during gas drainage, explores the migration mechanism and distribution pattern of coal seam gas, and analyzes the gas migration mechanism on the multiphysics simulation software COMSOL Multiphysics. The research results show that: under the action of different stress fields, the gas seepage is related to water content of the coal seam. Before failure, the seepage rate is negatively correlated with water content. After failure, the negative correlation changed to positive correlation. Under the cyclic stress field, the seepage rate first decreased and then increased with the growth in the strain. The COMSOL Multiphysics simulation reveals that, with the increase in the drilling distance, the gas pressure around the borehole with seepage was greater than that without seepage. The research findings provide the theoretical basis and a mathematical model for the migration of gas seepage in deep coal seams.
\end{abstract}

\section{INTRODUCTION}

Most of the coal in China is exploited via underground mining, in which the gas pressure increases with the mining intensity and depth. However, Chinese coal mines encounter various dynamic disasters arising from the following factors: complex geological conditions, harsh working environment, backward technical equipment and chaotic safety management $[1,2]$. Compared with developed countries, China faces a high difficulty in mining the gas from coal reservoirs. The relevant research and technology in China far from mature [3].

The gas-bearing coal seam is a large and complex adsorption, diffusion and seepage system. The micropores in the coal seam have adsorption and sedimentation effects, while the other pores have complicated diffusion and seepage effects. These effects, coupled with the seepage effect of micropores, make the gas completely free and dispersed [4]. In fact, there is an internal law with gas migration. In the coal seam, the gas migration and distribution are a long-term dynamic process, under the combined effects of stress field, diffusion field and seepage field. The seepage into the coal seam is influenced by crustal stress, the Klinkenberg effect, gas stress, adsorption, and effective stress and porosity. The pumping of coal seam gas causes a pressure difference between the gas layers in the coal seam. Hence, the original equilibrium state of the gasbearing reservoir ceases to exist. Then, the gas starts seep from the coal seam into the upper and lower surrounding rocks [5].

The coal seam is a porous medium with complex pores and fissures. The greater the gas drainage pressure in the coal seam, the faster the gas flow rate, and the higher the gas drainage rate. Some scholars found that the gas seepage in coal rock samples is not entirely reversible, that is, there is a lag between gas seepage and desorption in the coal seam [6]. Pawar et al. [7] improved the Langmuir isotherm adsorption model based on the migration law of gas in the coal seam, creating a new gas migration model.

The existing studies on the seepage during gas drainage mainly focus on the migration law of coal seam gas. However, there is little report on numerical simulation of gas migration. To make up for this gap, this paper probes deep into the seepage process during gas drainage, explores the migration mechanism and distribution pattern of coal seam gas, and analyzes the gas migration mechanism on the multiphysics simulation software COMSOL Multiphysics.

\section{MIGRATION MECHANISM OF COAL SEAM GAS}

The coal seam is the source of coal seam gas, which can be characterized by density, gravity, viscosity and saturation. In the coal seam, the gas is either adsorbed in the pores or free in the fractures $[8,9]$. For the gas adsorbed in the pores, the total adsorption amount can be computed by the Langmuir adsorption equation:

$$
\mathrm{A}_{1}=\frac{a_{t} a_{P a_{m}} p p_{n}}{\left(1+a_{p} p\right) R T}
$$

where, $a_{t}, a_{p}$, and am are the maximum adsorption capacity, pressure and combustible mass of coal at a specific temperature; $p$ is the adsorption equilibrium force; $p_{n}$ is the standard atmospheric pressure; $R$ is the gas constant; $T$ is the coal rock temperature. 
Meanwhile, the free gas content can be described by the ideal gas state equation:

$$
\mathrm{A}_{2}=\rho \xi
$$

where, $\rho$ is the gas density; $\xi$ is the void ratio of coal seam.

During gas drainage, the gas will seep out of the coal seam. The gas migration in the coal seam can be divided into diffusion and seepage. The diffusion of coal seam gas includes Northon diffusion, surface diffusion and volume diffusion. The unsteady diffusion system of the gas can be explained by Fick's $2^{\text {nd }}$ law of diffusion [10]. The gas seepage refers to the flow of the gas fluid through pores in the coal seam under the pressure difference. This process can be interpreted by Darcy's law. But the coal seam gas is in a gas-liquid two-phase state. Considering the capillary pressure and gravity, the Darcy's law for gas seepage can be expressed as:

$$
\mathrm{V}=-\frac{k}{\mu} \nabla(\mathrm{p}+\rho \mathrm{gH})
$$

where, $k$ is the permeability; $\mu$ is the viscosity coefficient of the gas fluid; $p$ is pressure; $\rho$ is density; $g$ is gravitational acceleration; $\mathrm{H}$ is the hydraulic head. Figure 1 illustrates the three phases of gas migration, namely, single-phase flow, unsaturated flow and two-phase flow. In the first phase, the gas flows as a liquid; in the latter two phases, the gas migrates as both liquid and gas.

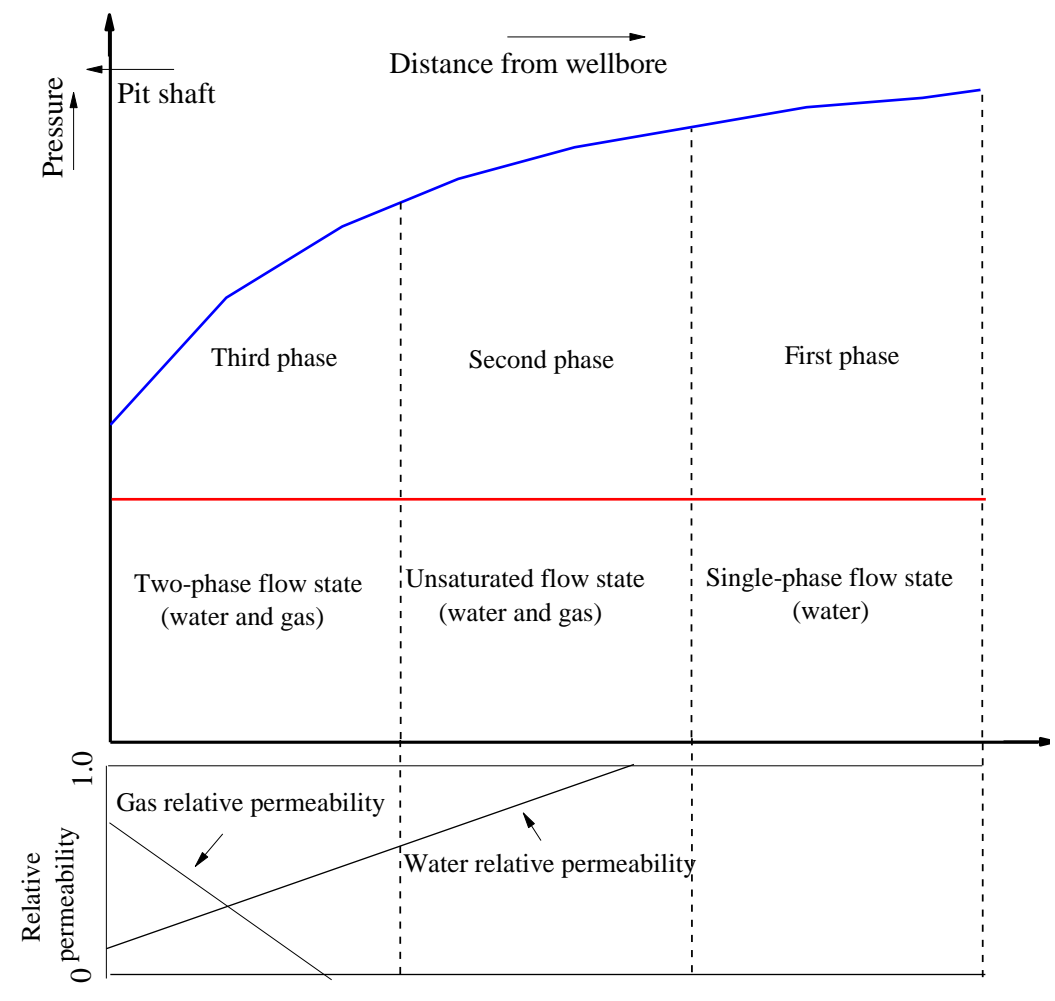

Figure 1. The three phases of gas migration

\section{GAS SEEPAGE TESTS UNDER DIFFERENT STRESS FIELDS}

\subsection{Gas seepage tests under mining stress field}

The mining stress field affects the strength of the coal seam and the migration of coal seam gas. Under the mining stress field, the higher the mining stress, the more frequent the sudden dynamic disasters in the coal mine [11]. In this paper, gas seepage in the coal seam is tested under the action of mining stress field. The data on gas seepage were collected from the disturbed coal seam of the Tenth Coalmine of Pingdingshan Tianan Coal Mining Co., Ltd. (Henan, China). Figure 2 presents the isothermal adsorption curve and the seepage pressure of gas. It can be seen that there exists a critical seepage pressure and that the gas seepage relies on the gas saturation in the coal seam.

In our gas seepage tests under mining stress field, the gas seepage rates of two coal samples were tested by a three-axis servo test device under four states with different water contents, namely, the dry state, the unsaturated state, the natural state and the saturated state. The seepage rates of coal samples after failure are displayed in Figure 3. It can be seen that the seepage rate of coal samples after failure increased with the water content. The seepage rates of the unsaturated state, the natural state and the saturated state were respectively $59.87 \%, 63.55 \%$ and $125.08 \%$ higher than that of the dry state. The variation in seepage rate is the result of water content. Water reduces the cohesive force and internal friction coefficient of the coal samples. The greater the water content, the weaker and more damaged the coal samples, and the faster the gas seepage $[12,13]$.

Figure 4 shows the relationship between the effective seepage rate and axial strain of coal samples under different states. It can be inferred that the coal sample with higher water content exhibited greater strains in the yielding stage and the failure stage. Before failure, the seepage rate is negatively correlated with water content in the coal samples. After failure, the negative correlation changed to positive correlation. 


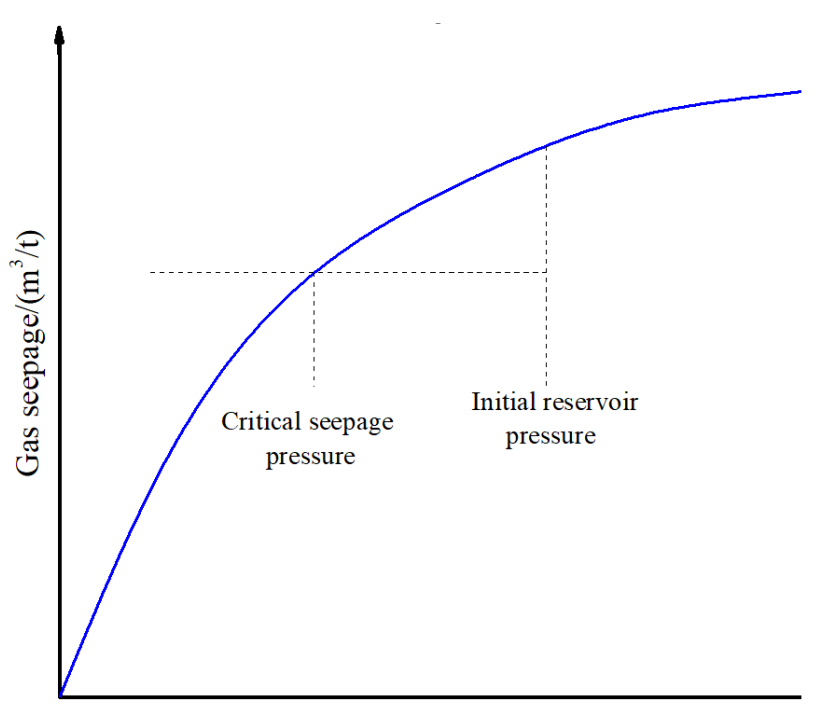

Pressure/ $\mathrm{MPa}$

Figure 2. The isothermal adsorption curve and the seepage pressure of gas

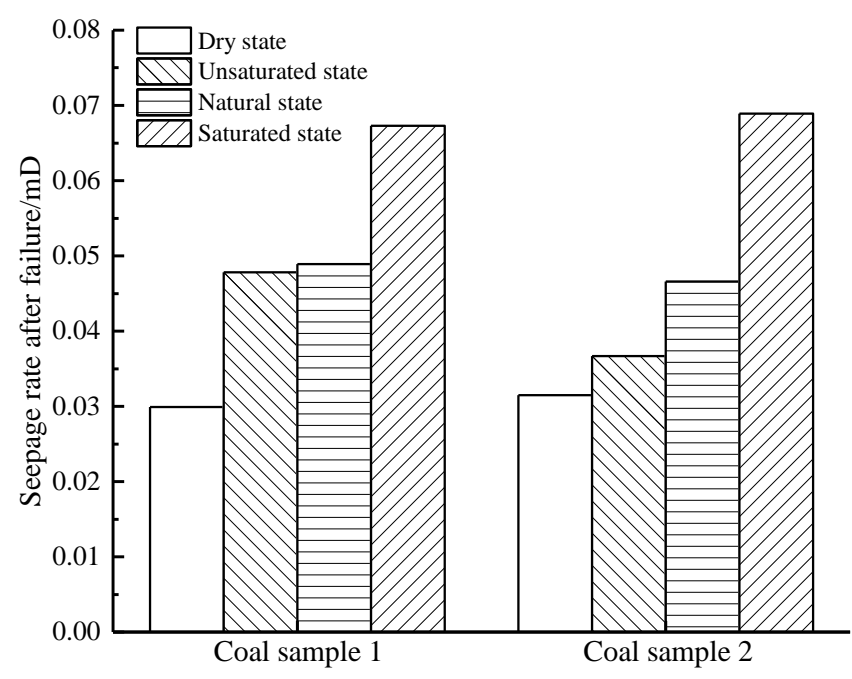

Figure 3. The seepage rates of coal samples after failure

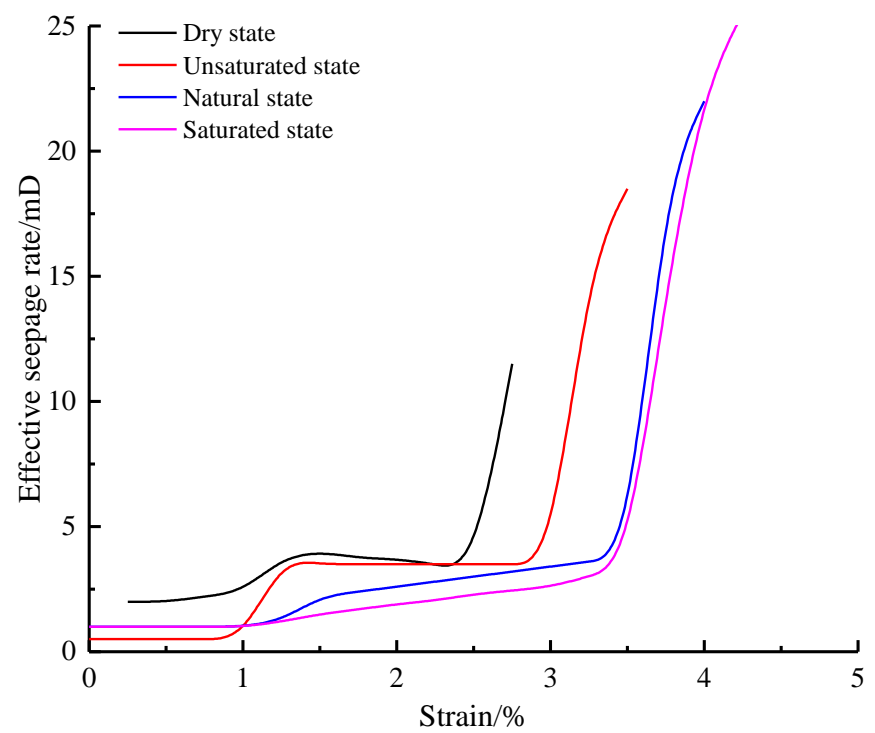

Figure 4. The relationship between the effective seepage rate and axial strain of coal samples under different states

\subsection{Gas seepage tests under cyclic stress field}

Under the vibration of cyclic load, the coal seam will be subjected to a cyclic stress, which affects the gas seepage in coal. The gas seepage tests under cyclic stress field use the same device as those under mining stress field. The loading/unloading was conducted in stages under the inlet gas pressure of $0.5 \mathrm{MPa}$. Without changing the inlet gas pressure, the staged loading/unloading was carried out after the coal samples reached the equilibrium of gas adsorption. Figure 5 shows the relationship between the number of stress cycles and the relative recovery rate of the seepage rate of the two coal samples. It can be seen that, with the increase in the number of stress cycles (i.e. the growth in cumulative residual deformation), the relative recovery rate of the seepage rate gradually increased in both coal samples. For coal sample 1, the recovery rate of the seepage rate increased rapidly in the second stress cycle. For coal sample 2, the recovery rate of the seepage rate did not undergo rapid increase until the sixth stress cycle.

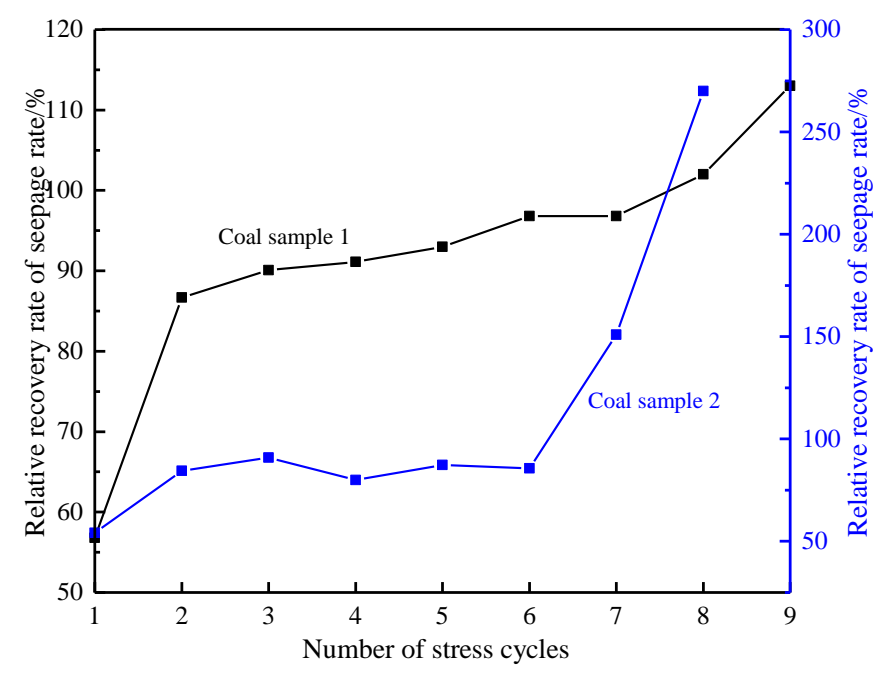

Figure 5. The relationship between the number of stress cycles and the relative recovery rate of the seepage rate of the two coal samples

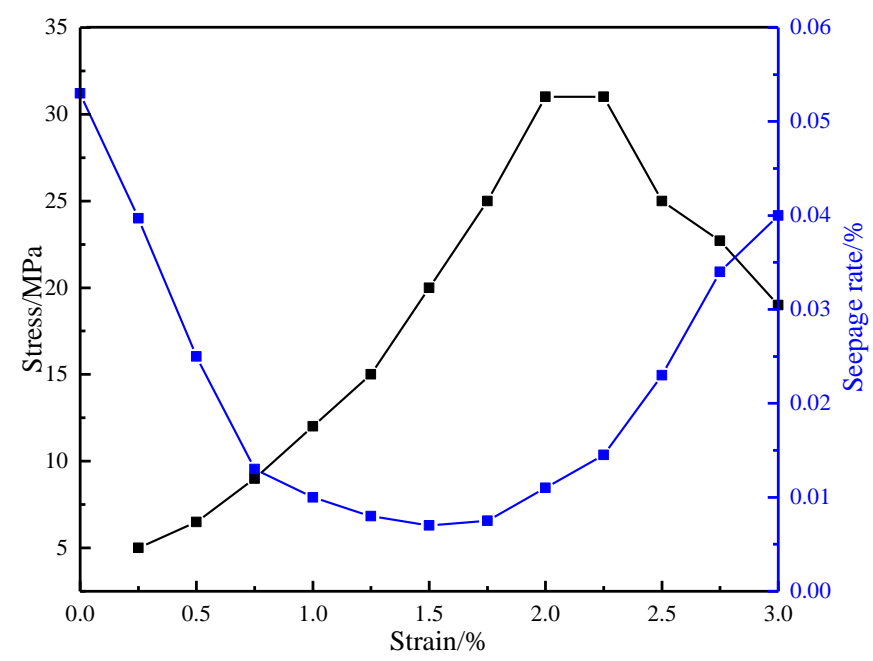

Figure 6. The axial stress-strain and seepage rate-strain curves of coal sample 1

Figure 6 displays the axial stress-strain and seepage rate- 
strain curves of coal sample 1. It can be learned that, the strain increased with the stress. The stress started to decrease once the strain climbed up to 2.0. Besides, the seepage rate first reduced and then increased with the growth in strain.

\section{NUMERICAL SIMULATION OF GAS MIGRATION IN COAL SEAM}

\subsection{Numerical model of gas migration in coal seam}

The migration of gas in the coal seam, a porous medium, was simulated with a mathematical model. It is assumed that the gas migrates as a pure gas flow, only undergoes mass exchange and obeys the Fick's $2^{\text {nd }}$ law of diffusion. In the reservoir, the migration and diffusion of gas changes with time. According to the law of conservation of mass, the variation of gas diffusion per unit time of the micro-element in the transverse direction equals difference between the inflow mass and the outflow mass, plus the mass generated at the source:

$m_{x} d y d z-\left(m_{x}+\frac{\partial m_{x}}{\partial x} d x\right) d y d z-q_{x} d x d y d z=-\frac{\partial m_{x}}{\partial x} d x d y d z-q_{x} d x d y d z$ $\mathrm{m}_{\mathrm{y}} \mathrm{dydz}-\left(\mathrm{m}_{\mathrm{y}}+\frac{\partial m_{y}}{\partial y} \mathrm{dx}\right) \mathrm{dydz}-\mathrm{q}_{\mathrm{y}} \mathrm{dxdydz}=-\frac{\partial m_{y}}{\partial y} \mathrm{dxdydz}-\mathrm{q}_{\mathrm{y}} \mathrm{dxdydz}$ $\mathrm{m}_{\mathrm{z}} \mathrm{dydz}-\left(\mathrm{m}_{\mathrm{z}}+\frac{\partial m_{\mathrm{z}}}{\partial z} \mathrm{dx}\right) \mathrm{dydz}-\mathrm{q}_{\mathrm{z}} \mathrm{dxdydz}=-\frac{\partial m_{\mathrm{z}}}{\partial z} \mathrm{dxdydz}-\mathrm{q}_{\mathrm{z}} \mathrm{dxdydz}$

The total gas diffusion variation in the micro-element can be obtained as:

$$
-\left(\frac{\partial m_{x}}{\partial x}+\frac{\partial m_{y}}{\partial y}+\frac{\partial m_{z}}{\partial z}\right) d x d y d z-q d x d y d z
$$

Let $C$ be the flow rate of the diffusing gas in the microelement. Then, the time-varying mass increment of gas diffusion can be expressed as:

$$
\frac{\partial C}{\partial t} \mathrm{dxdydz}
$$

Thus, the gas diffusion in the micro-element satisfies the following differential equation:

$$
\frac{\partial C}{\partial t}=-\left(\frac{\partial m_{x}}{\partial x}+\frac{\partial m_{y}}{\partial y}+\frac{\partial m_{z}}{\partial z}\right)-\mathrm{q}
$$

\subsection{Numerical simulation of gas migration in coal seam}

The software COMSOL Multiphysics embeds modelling tools in a fully open architecture. With a powerful meshing function, the software can solve multi-field coupling problems by solving differential equations. Therefore, COMSOL Multiphysics was adopted to simulate the diffusion and seepage fields of gas migration in Erdos Coalmine of Shenhua Group, using the differential equation (7) for gas diffusion. The boundary conditions are as follows: the coal seam is distributed in the horizontal direction; the effects of working face on pressure are ignored; the coal seam has the same initial gas pressure with the upper and lower surrounding rocks. The simulation was conducted with and without gas seepage.

Figures 7 and 8 present the gas pressure curves without and with seepage, respectively. It can be seen that, with the increase in the drilling distance, the gas pressure around the borehole with seepage was greater than that without seepage; with the progress of gas drainage, the scope of gas pressure decline widened, and the gas drainage in the reservoir was supplemented by the gas from the upper and lower coal seams (surrounding rocks).

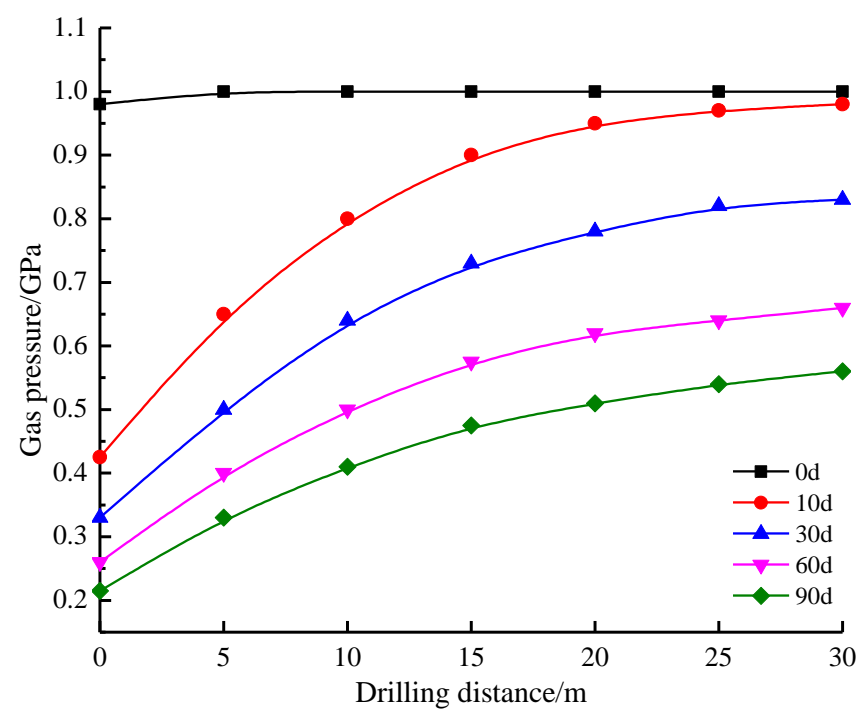

Figure 7. Gas pressure curve without seepage

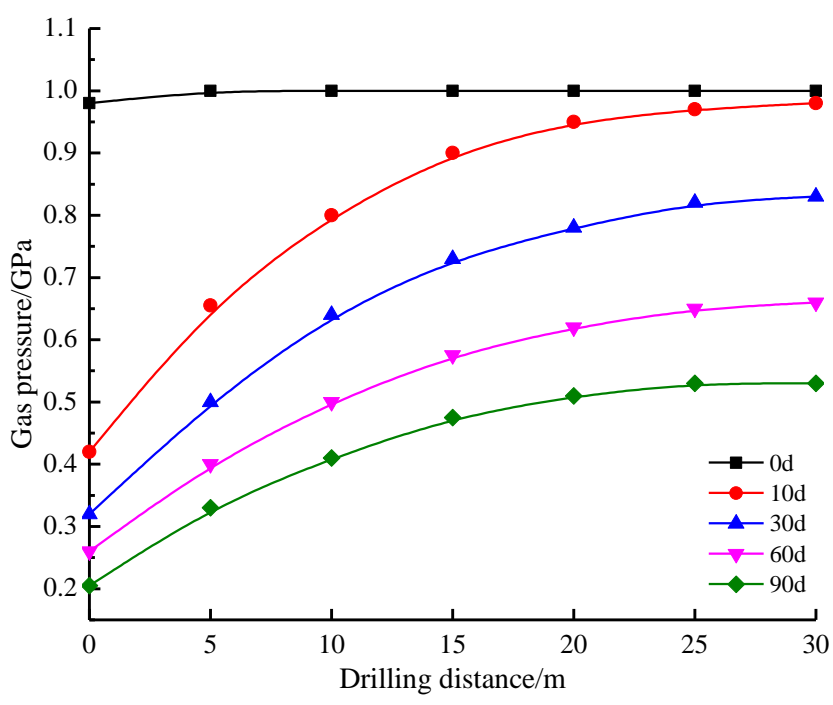

Figure 8. Gas pressure curve with seepage

\section{CONCLUSIONS}

Focusing on the seepage in gas drainage, this paper explores the migration mechanism and distribution pattern of coal seam gas, and analyzes the gas migration mechanism on the multiphysics simulation software COMSOL Multiphysics. The main conclusions are as follows:

(1) The seepage rate of coal samples after failure increased with the water content. The variation in seepage rate is the result of water content. Water reduces the cohesive force and internal friction coefficient of the coal samples. The greater the water content, the weaker and more damaged the coal samples, and the faster the gas seepage.

(2) The strain increased with the stress. The stress started to decrease once the strain climbed up to 2.0. Besides, the seepage rate first reduced and then increased with the growth in strain.

(3) With the increase in the drilling distance, the gas 
pressure around the borehole with seepage was greater than that without seepage; with the progress of gas drainage, the scope of gas pressure decline widened, and the gas drainage in the reservoir was supplemented by the gas from the upper and lower coal seams (surrounding rocks).

\section{REFERENCES}

[1] Cao, J., Li, W. (2017). Numerical simulation of gas migration into mining-induced fracture network in the Goaf. International Journal of Mining Science and Technology, 27(4): 681-685. https://doi.org/10.1016/j.ijmst.2017.05.015

[2] Uchida, S., Lin, J.S., Myshakin, E.M., Seol, Y., Boswell, R. (2018). Numerical simulations of sand migration during gas production in hydrate-bearing sands interbedded with thin mud layers at site nghp-02-16. Marine and Petroleum Geology. https://doi.org/10.1016/j.marpetgeo.2018.10.04

[3] Xie, J., Chen, J. (2014). Numerical simulation of landfill gas migration around a vertical extraction well in Xiangshan landfill. Energy Sources, Part A: Recovery, Utilization, and Environmental Effects, 36(16): 17641773. https://doi.org/10.1080/15567036.2011.559523

[4] Roy, N., Molson, J., Lemieux, J.M., Stempvoort, D.V., Nowamooz, A. (2016). Three-dimensional numerical simulations of methane gas migration from decommissioned hydrocarbon production wells into shallow aquifers. Water Resources Research, 52(7): 5598-5618. https://doi.org/10.1002/2016WR018686

[5] Amaziane, B., Ossmani, M.E. (2012). Numerical simulation of gas migration through engineered and geological barriers for a deep repository for radioactive waste. Computing and Visualization in Science, 15(1): 320. https://doi.org/10.1007/s00791-013-0196-1

[6] Zhang, J.R., Wang, C.Q., Dong, D.W. (2011). Numerical simulation study of gob air leakage field and gas migration regularity in downlink ventilation. Journal of Coal Science and Engineering, 17(3): 316-320. https://doi.org/10.1007/s12404-011-0317-8

[7] Pawar, R.J., Watson, T.L., Gable, C.W. (2009). Numerical simulation of $\mathrm{Co}_{2}$ leakage through abandoned wells: Model for an abandoned site with observed gas migration in Alberta, Canada. Energy Procedia, 1(1): 3625-3632. https://doi.org/10.1016/j.egypro.2009.02.158

[8] Sharma, P., Saroj. (2015). Discovery of classification rules using distributed genetic algorithm. Procedia Computer Science, 46: 276-284. https://doi.org/10.1016/j.procs.2015.02.021

[9] Yue, J., Wang, Z., Chen, J. (2018). Investigation of timing characteristics of the imbibition height of remolded coal without gas. Energy Sources Part A Recovery Utilization and Environmental Effects, 41(2): 156-166. https://doi.org/10.1080/15567036.2018.1505980

[10] Liu, T., Lin, B., Yang, W., Zhai, C., Liu, T. (2017). Coal permeability evolution and gas migration under nonequilibrium state. Transport in Porous Media, 118(3): 393-416. https://doi.org/10.1007/s11242-017-0862-8

[11] Wu, H., Zhang, B., Qiu, Y., Luo, G., Yao, H. (2016). Experiment study on mercury migration across wet flue gas desulfurization slurry under oxy-coal combustion atmosphere. Fuel, 181: 1184-1190. https://doi.org/10.1016/j.fuel.2016.03.105

[12] Peng, S.J., Xu, J., Yin, G.Z., Liu, D., Wang, W.Z. (2012). Spatial-temporal evolution of gas migration pathways in coal during shear loading. International Journal of Mining Science and Technology, 22(6): 769-773. https://doi.org/10.1016/j.ijmst.2012.11.009

[13] Zheng, C., Zheng, H., Yang, Z., Liu, S., Gao, X. (2018). Experimental study on the evaporation and chlorine migration of desulfurization wastewater in flue gas. Environmental Science and Pollution Research, 26(5): 4791-4800. https://doi.org/10.1007/s11356-018-3816-y 